\title{
Pasquale Petrone e a Geografia na USP
}

\section{7 studos Avancados - Quando o senhor ingressou na Faculdade de Filosofia, por que a escolbeu e por que se dedicou à área de Geografia?}

Pasquale Petrone - O ingresso na Faculdade de Filosofia foi decorrência da necessidade de encontrar solução para um problema pessoal que se criou à época da Segunda Guerra Mundial. Nasci na Itália, e na década de 1930 estudava em uma escola italiana. Embora frequientasse ao mesmo tempo os cursos que obedeciam ao currículo brasileiro e ao currículo italiano, meu objetivo era retornar à Itália onde tencionava cursar a Universidade, enfim, completar os estudos. $\mathrm{Na}$ época o curso médio das escolas brasileiras compreendia cinco séries em nível ginasial, enquanto o curso médio italiano incluía o ginásio, com quatro séries e o liceu - científico ou clássico - com três séries. Quando terminei a 4⿳亠丷a série ginasial, em lugar de cursar a $5^{\mathbf{a}}$ do currículo brasileiro, ingressei no Liceu Científico italiano, dada a intenção de retornar à Itália. Sobreveio a guerra, verificou-se o rompimento das relaçóes entre Brasil e Itália, os cursos italianos existentes no Brasil foram fechados, a escola onde estudava sofreu intervenção federal. Com isso, meus estudos no Liceu italiano foram encerrados quando iniciava a $2^{a}$ série.

\section{$O$ ingresso na Geografia}

\section{EA - Era no Dante Alighieri?}

$P P$ - Foi no Dante Alighieri. Na ocasião, não tive outra solução senão retomar o currículo brasileiro freqüientando a $5^{\mathbf{a}}$ série ginasial. Com a reforma do ensino que se verificou naquela época, em lugar de ingressar no Colégio Universitário, depois de concluída a 5ª série, passei a cursar $02^{\circ}$ ano do Colegial Científico, curso que compreendia três anos de estudos. Foi quando tive a oportunidade de tomar conhecimento da existência da Faculdade de Filosofia e, pormenor relevante, naquele ano não haveria necessidade de completar as três séries colegiais para tentar o ingresso nessa escola. Isso significava recuperar parte do tempo, embora em nenhum momento tenha lamentado o tempo empregado no curso italiano. Ao decidir ingressar na Faculdade de Filosofia, optei pelo Curso de Geografia e História, de um lado porque realmente gostava muito de História e, de outro, porque começava a 
interessar-me pela Geografia. Uma das conseqüências da intervenção federal na escola em que estudava fora a contrataçáo da vários professores brasileiros, dentro da perspectiva de nacionalizaçáo da escola. Um desses professores foi João Dias da Silveira, de Geografia, e suas aulas contribuíram para que passasse a me interessar por esse ramo do conhecimento. Ingressei na Faculdade em 1944, ainda com interesse voltado para a História, mas, durante o curso, sempre mais atraído pela Geografia.

$E A$ - O senbor naio foi aluno do professor Deffontaines, mas do professor Monbeig, naio ê?

$P P$ - Fui aluno do professor Pierre Monbeig durante todo o curso. Não fui aluno do professor Pierre Deffontaines no curso regular, mas tive oportunidade de conhecê-lo relativamente bem $\mathrm{em}$ atividades extracurriculares, inclusive quando retornou ao Brasil para proferir palestras.

\section{O impacto da criação do FFCL}

$E A$ - Como o senbor vt o impacto da criajáo da Faculdade na drea de Geografia? Pergunto porque entrevistamos o professor Eduardo Franfa e ele disse que, na drea de Historia o impacto talvez tenba sido menor que em outras direas devido à influencia, naquela época, de professores brasileiros de renome na área de Historia do Brasil, como Tannay e Alfredo Ellis, que seguiam uma orientafáto tradicional. Em relafäo à Geografia, o senbor acha que a Faculdade de Filosofia levou a uma mudanga no ensino e nas pesquisas?

$P P$ - Creio que a presença da Faculdade de Filosofia foi extraordinária em termos de mudança cultural em geral. No caso específico da Geografia convém lembrar a existência no Brasil, já antes da criaçáo da Faculdade, de alguns nomes expressivos. Lembraria principalmente $o$ professor Delgado de Carvalho, com formaçáo na França, autor de livros muito conhecidos e ainda hoje importantes. Mas o fato de já existirem na Geografia algumas pessoas até com grande renome, não significa que a Faculdade não tenha realmente revolucionado. Na verdade, as pessoas a que me referi, pouco numerosas, eram como peixes fora d'água, no sentido de que o ambiente cultural, no caso específico da Geografia, não era suficientemente amadurecido para que sua produção científica fosse não apenas reconhecida, mas também frutificasse. Determinados livros didáticos, a exemplo dos de Delgado de Carvalho, nem sempre tiveram a penetraçăo que mereciam porque estavam muito acima do que o mercado cultural poderia absorver.

Com a criaçăo da Faculdade de Filosofia, esse quadro pôde ser 
sensivelmente modificado. A nova Faculdade logo demonstrou ser um vigoroso instrumento de mudança. Năo se tratava mais da atividade de uma só pessoa, ou de poucas pessoas, mas de toda uma instituiçảo e do papel por ela representado em todos os campos da vida cultural. As mudanças verificaram-se, e no caso específico da Geografia, foram muito expressivas. Não sei se poderia afirmar que o certificado de nascimento da ciência geográfica no Brasil estaria relacionado com a criaçáo da Faculdade de Filosofia, Ciências e Letras da USP, ou mesmo com a Faculdade Nacional de Geografia, do Rio de Janeiro. Acredito que tudo tenha ocorrido no conjunto de um processo de mudança mais amplo, naturalmente muito mais importante do que a relativamente modesta mudança no campo da Geografia, apenas parte do processo geral. É que a presença da Faculdade de Filosofia implicou antes de mais nada, revoluçáo de costumes, cultural e, naturalmente, bem mais ampla e significativa do papel reservado às mudanças na condução da ciência geográfica.

EA - Antes da criafão da Faculdade de Filosofia da USP o ensino de Geografia tambem era ligado a pesquisas ou isso foi uma contribuigão da Faculdade?

$P P$ - Foi fundamentalmente uma contribuição da Faculdade. Convém, entretanto, situar melhor a questão. Não raro percebe-se a tendência, em determinados depoimentos, no sentido de valorizar o que veio com a criaçáo da Faculdade, o que me parece justo. Seria o último a não querer reconhecer o papel da Faculdade mas, paralelamente, conviria não desconhecer o que já se verificava antes de sua criação, o que significaria desconhecer uma realidade anterior, cultural, que não era muito pobre - especialmente a realidade paulista. Acredito que em São Paulo existiu, desde as últimas décadas do século passado, um verdadeiro projeto de modernização, naturalmente estreitamente relacionado com o processo de desenvolvimento econômico e, implicitamente, com fatos como expansão da lavoura cafeeira, incentivo ao ingresso de imigrantes, crescimento industrial, desenvolvimento das ferrovias, entre vários outros. Um dos mais significativos aspectos desse projeto percebe-se, por exemplo, na criação de instituiçōes como o Instituto Butantan, o Instituto Agronômico, de Campinas, a Escola de Agricultura Luiz de Queiroz, de Piracicaba, a Escola Politécnica, o Instituto Geográfico e Geológico, o Instituto Biológico e assim sucessivamente. A mim, parece que a Faculdade de Filosofia deva ser considerada também fruto desse projeto, talvez um dos mais importantes. Sob tal aspecto, a Faculdade de Filosofia não foi tão somente instrumento de processos de mudança, mas também decorrência desses processos. É no bojo do processo decorrente do projeto referido que se propóem a Faculdade de 
Filosofia e as mudanças decorrentes de sua presença no campo cultural em geral, nos campos específicos do ensino e da pesquisa.

Efetivamente, a principal mudança relacionada com a presença da Faculdade de Filosofia implicou significativas repercussóes culturais e, naturalmente, importantes repercussóes no campo do ensino e da pesquisa, principalmente no íntimo relacionamento de uma e outra coisa. É muito frequiente insistir na interligação do ensino e da pesquisa como característica fundamental das atividades da Faculdade de Filosofia; na verdade, essa foi a novidade fundamental. No caso específico da Geografia, o geógrafo passou a ir com muita freqüência ao campo, deixou de ser livresco, passou a estudar, pesquisar e produzir e, nesse sentido, a Faculdade contribuiu para mudanças muito expressivas. Náo se tratou apenas de enriquecer o ensino com o aporte da atividade de pesquisa, mas também de enriquecer a vida cultural em geral $e$ as atividades científicas em particular através do que hoje denominamos de atividades multidisciplinares. Porque, na verdade, é com a Faculdade de Filosofia que geógrafos, historiadores, geólogos, biólogos, antropólogos, sociólogos e outros passaram a trabalhar muitas vezes em conjunto. No caso da Geografia tal fato ficou nitidamente claro. Para comprovaçáo desse fato, creio suficiente um exemplo. A primeira revista efetivamente científica dedicada à Geografia no Brasil, dentro desses novos padróes, chamou-se Geografia e foi criada em Sáo Paulo no ano de 1934, justamente no mesmo ano da criação da Faculdade de Filosofia. A revista surgiu sob os auspícios da Associação dos Geógrafos Brasileiros, também fundada na mesma época, sempre em Sáo Paulo, seguindo orientação dos professores franceses, primeiramente Pierre Deffontaines e depois Pierre Monbeig. Essa publicação, além de geógrafos, contava também com a participação de pessoas de outros campos, a exemplo de Luiz Flores de Morais Rego, Rubem Borba de Moraes, Caio Prado Júnior e muitos outros. Nela colaboraram geólogos, sociólogos, historiadores e cientistas de outros campos. Representava uma nova visão de trabalhar com a cultura, de produzir cultura, radicalmente diferente daquilo que existira até então. De um lado, diferente porque não era compartimentada, isolada e, de outro lado, justamente porque não se atinha mais a só haurir o que já vinha nos livros, e porque era voltada para a compreensão da realidade brasileira até entáo razoavelmente ignorada, náo sempre ignorada, é verdade, mas não necessariamente bem conhecida.

\section{O desenvolvimento com Pierre Monbeig}

EA - O professor Monbeig foi muito importante na área de Geografia ou na Faculdade de uma maneira geral? 
$P P$ - Creio que especialmente para a Geografia foi fundamental. Foi o primeiro catedrático de Geografia, inicialmente uma cátedra única. Deffontaines ficou em São Paulo cerca de um ano, pouco tempo portanto, mas fundou a Associação dos Geógrafos Brasileiros. A consolidação das iniciativas de Pierre Deffontaines deveu-se a Pierre Monbeig. Monbeig permaneceu em São Paulo cerca de dez anos. Com ele, a cátedra única logo deu origem a três outras, em seguida a outras disciplinas até chegar a esse Departamento que atualmente, sozinho, é quase o triplo do que era quase toda a Faculdade de Filosofia da década de 1930 e primeiros anos da década de 1940. A importância do professor Pierre Monbeig foi realmente muito grande. Era excelente professor e excelente pesquisador. Nunca dissociava uma coisa da outra, orientava o estudante de modo a fazer com que a pesquisa ingressasse na sala de aula, assim como a experiência ganha na sala de aula fosse aproveitada no trabalho de campo, sempre com estreita interaçáo de ensino e pesquisa. turmas?

EA - Nas excursões que eram feitas ele também acompanbava as

$P P$ - Dirigia e acompanhava. Tive oportunidade de participar de várias excursóes que o professor Monbeig organizou, quer com assistentes, quer com alunos, com alunos e assistentes, com outros docentes etc. Algumas dessas excursóes direta ou indiretamente relacionavam-se com a realizaçáo de pesquisas do próprio docente. A partir de várias dessas excursões definiu-se o trabalho de Monbeig Pioneiros e plantadores do estado de São Paulo, com o qual doutorou-se na França. Parece-me importante o fato de que a pesquisa de Monbeig não se dissociava das atividades de pesquisas em geral, nem das atividades didáticas. Tudo acabava por resultar num conjunto harmonioso, em termos de crescimento do aluno, do assistente e dele mesmo, docente.

EA - Pelo que já li, ele dedicou-se mais à Geografia Humana. Isso era novidade aqui por os trabalhos anteriores no Brasil serem mais voltados ao campo da Geografia Física?

$P P$ - Realmente, a maior produção parece que se verificava no campo da Geografia Física. Na verdade, nem sempre se tratava de Geografia Física, mas de Geologia ou, de qualquer modo, de campos estreitamente relacionados com a Geografia Física. Convém não esquecer, entretanto, e como exemplo, que Delgado de Carvalho, embora tenha publicado livros interessando a Geografia Física, também dedicou-se à Geografia Humana. Estudiosos como Alfredo Ellis Júnior, antes de mais nada historiadores, também produziram Geografia Humana, embora mais em nível das obras didáticas. De qualquer modo, no conjunto, 
Monbeig enriqueceu sensivelmente esse campo de atividade científica. Parece-me interessante lembrar que a primeira tese de doutoramento defendida na Faculdade de Filosofia foi um trabalho de Geografia $\mathrm{Hu}-$ mana, dedicado ao estudo do porto de Santos, de autoria de Maria Conceiçáo Vicente de Carvalho e elaborada sob a orientaçăo do professor Pierre Monbeig.

\section{Associação dos Geógrafos Brasileiros e Instituto de Geografia} sileiros?

EA - Foi e é importante a criaģão da Associação dos Geógrafos Bra-

$P P$ - Acho que foi muito importante, e continua sendo importante. Foi importante assim como o foi a revista Geografia a que já me referi, a primeira publicação científica significativa voltada para a Geografia no país todo. A Associaçáo dos Geógrafos Brasileiros, fundada em Sáo Paulo, foi a primeira entidade voltada para uma Geografia científica. Năo se trata, com a afirmação acima, de menosprezar ou menoscabar o que já existia, a exemplo do Instituto Histórico e Geográfico, no Rio de Janeiro, em São Paulo, ou em outras partes do país. Mas é que as atividades dessas entidades tinham outro significado, embora freqüentemente de inegável importância, e sobre isso parece que não caibam dúvidas. Porém, dentro de uma perspectiva rigorosamente científica, a Associação dos Geógrafos Brasileiros inovou. Como organização foi pioneira, sob vários aspectos, dado que posteriormente outras entidades, voltadas para outros campos científicos, surgiram a partir do paradigma representado pela Associação dos Geógrafos Brasileiros. Pareceme importante, também, o fato de tal entidade ter surgido em São Paulo, de certa forma no bojo da Faculdade de Filosofia, e que tenha crescido sempre estreitamente vinculada à Universidade. Cabe insistir, embora autônoma, entidade particular e, portanto, não oficial, a Associação dos Geógrafos Brasileiros funcionou sempre em sintonia com a USP. Foram muitos os alunos da Universidade que tiveram a oportunidade de crescer intelectualmente freqüentando a Associaçáo.

\section{EA - Qual a importdncia do Instituto de Geografia da USP?}

$P P$ - O Instituto de Geografia surgiu no ano de 1963 , e tive a oportunidade de participar de todo o processo de sua criaçáo. Fui seu diretor de pesquisas e vice-diretor durante muitos anos, quer sob a direção do professor Aroldo de Azevedo, quer sob a direçáo do professor Aziz Nacib Ab'Saber. Quando o professor Ab'Saber deixou o Instituto, passei à condição de diretor, até a data de minha aposentadoria. 


\section{$E A$ - O Instituto naio existe mais?}

$P P$ - Responderei também à questão anterior. O Instituto de Geografia infelizmente năo existe mais. Seu surgimento verificou-se, antes de mais nada, pelo esforço realizado pelo professor Aroldo de Azevedo. Foi ele quem realmente mais batalhou pela sua criação. Vamos ver se consigo deixar claro qual o objetivo de sua criação. Na Faculdade de Filosofia, o Curso de Geografia sempre sofreu problemas relativamente sérios, decorrentes principalmente da incompreensão da própria natureza de suas atividades e, em conseqüência, de suas necessidades. Para alguns, seria um curso que deveria estar vinculado às ciências naturais, enquanto, para outros, um curso nitidamente vinculado às ciências humanas, especificamente às ciências sociais. Desde quando foi criado, permaneceu vinculado às ciências sociais. Inicialmente, esse fato verificou-se porque na prática, no seio da entáo Subseçáo de Geografia e História, surgiu como linha auxiliar do curso de História. Tratava-se de uma das formas tradicionais de entender a Geografia, campo que deveria subsidiar a História. $O$ fato de o curso de Geografia ter crescido, e muito, não contribuju para modificar significativamente essa situação. Como conseqüência, o curso de Geografia durante muitos anos foi visto como necessitado praticamente de sala de aula, carteiras e biblioteca. Em termos práticos, tal situação significava que outros cursos, a exemplo de Química, Geologia, Botânica e muitos mais, que necessitavam e dispunham de laboratórios, automaticamente recebiam recursos específicos para o desenvolvimento de suas atividades, embora caiba reconhecer que nem sempre de maneira satisfatória. Curso como o de Geografia não só exigia a instalaçáo de laboratórios, mas também de intensas atividades de campo e os recursos que recebia eram decididamente insuficientes. Durante muitos anos, por exemplo, o Departamento de Geografia somente pôde realizar excursóes com seus alunos graças ao empréstimo de ónibus de outras unidades da Universidade, entre elas a Faculdade de Medicina Veterinária. Quando, finalmente, depois de muito batalhar, conseguiu que fosse adquirido um ônibus para excursōes, o veículo veio para toda a Faculdade. Com a criaçáo do Instituto de Geografia na condiçáo de uma das unidades da USP, surgia uma entidade com direito a orçamento próprio, podendo, embora a partir de recursos parcos, promover pesquisas, cursos especiais, manter uma linha editorial, organizar laboratórios, inclusive um arquivo de fotografias aéreas e outras muitas atividades. Infelizmente concluiu-se, dentro da Universidade, que com a existência do Instituto de Geografia verificava-se duplicidade de atividades e, por isso, deveria ser desativado. O Departamento de Geografia recebeu grande parte do acervo do Instituto, porém sem o acompanhamento dos recursos que seriam desejáveis e necessários. 


\section{O relacionamento da Geografia com outras áreas}

$E A$ - Quando o senbor passou pela Faculdade, antes como aluno, depois como assistente e docente, naquela fase inicial, como era o relacionamento com as outras dreas, como Historia Natural?

$P P$ - O relacionamento com outras áreas era muito mais intenso que hoje. Tal fato verificava-se, antes de mais nada, porque as então

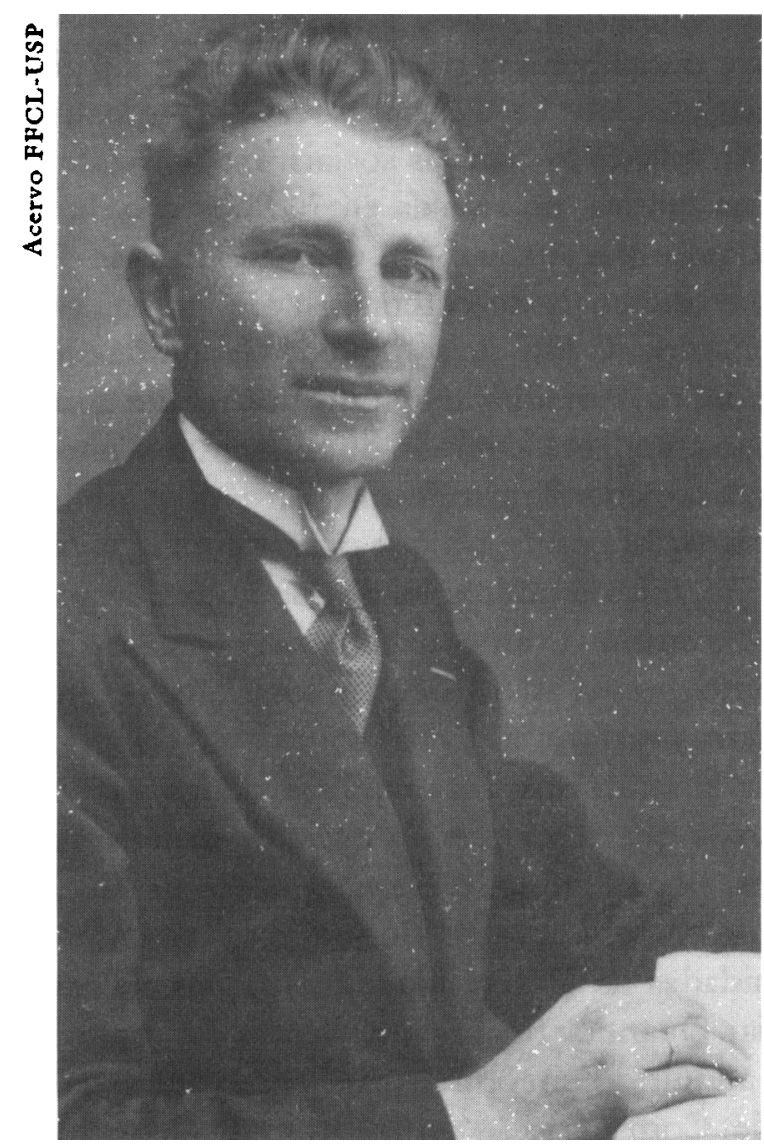

Pierre Deffontaines

subseçōes da Faculdade de Filosofia, Geografia e História, Letras Clássicas, Ciências Sociais, Química, História Natural, Letras Neo-Latinas, Física, Matemática, Letras Anglo-Germânicas, Filosofia, que pertenciam a uma mesma escola, atualmente em grande parte formam institutos separados. É evidente que antes, mesmo localizados em prédios diferentes, tais setores da Faculdade podiam, e $\mathrm{m}$ certos casos deviam, relacionar-se de forma mais estreita. Por outro lado, o ambiente existente 
na Faculdade propiciava e favorecia o inter-relacionamento cultural. Em outras palavras, o fato de ser um aluno do Curso de Geografia e História não impedia que houvesse interesse pelo que se verificava, por exemplo, em Letras ou História Natural. Na condição de aluno, acompanhei todos os passos de um Concurso para a Cátedra de Literatura Brasileira. Aparentemente, tratava-se de alguma coisa distante do que deveria ser do interesse de um aluno de História e Geografia. Entretanto, o interesse existia por parte de alunos desse e de outros cursos da Faculdade. Verificava-se um rico relacionamento entre os estudantes dos diferentes cursos, assim como existia riqueza na relação entre os docentes de toda a escola, e de diferentes unidades da Universidade. Em uma excursão realizada ao Norte do Paraná, sob a direçáo do professor Pierre Monbeig, em 1946, participaram alunos de Geografia e professores de Geografia, História, Botânica, Geologia, Politécnica, entre outros.

Aparentemente verificou-se uma mudança quanto ao aspecto referido. A compartimentaçáo e $o$ isolamento tornaram-se mais fortes. Não sei até que ponto estou sendo correto na afirmaçáo, mesmo porque agora não tenho muito conhecimento do que esteja ocorrendo, mas tudo parece indicar que atualmente as condiçóes náo são as mesmas. Parto de minha experiência pessoal, certamente bem menos rica que a de muitos de meus colegas dos diferentes cursos. Embora aluno de Geografia e História, sempre que possível freqüentava aulas de Literatura Portuguesa e Literatura Brasileira. Os professores, em nenhum caso, opunham qualquer restriçăo à presença do estudante năo regularmente matriculado para aquela disciplina. Assisti aulas de Lourival Gomes Machado muitas vezes. Náo se tratava de obter um certificado, mas tão somente de interesse. Muitíssimos, como eu, faziam a mesma coisa. $O$ enriquecimento cultural inevitavelmente beneficiava $o$ aluno no seu próprio curso. Convém ter em mente que em meados da década de 1940 toda a Faculdade, com todas as atuais unidades autônomas, não contava mais de quinhentos estudantes. Atualmente, apenas o curso de Geografia deve estar com um milhar de alunos. Acredito que só tal fato já contribua para explicar certas diferenças.

EA - Com toda essa experiencia que o senhor tem de docencia, na área de Geografia, com tantos campos e dreas nopas, qual deperia ser a orientafáo para os nopos pesquisadores? $O$ que o senhor acrescentaria, que recomendaçós daria, que enfase o senhor colocaria nos dipersos campos da Geografia?

$P P$ - Parece-me muito difícil responder satisfatoriamente a essas questōes. De qualquer forma, atrevo-me a sugerir que um caminho a ser tomado, antes de mais nada e fundamentalmente, é o de nunca abraçar qualquer diretriz científica com qualquer tipo de fanatismo ideológico. 
As trincheiras, em ciência, talvez tenham significado aparente nos momentos em que sáo valorizadas, mas acabam por perderem consistência com o passar do tempo. $\mathrm{Na}$ condição de aluno recusei-me a receber rótulos de possibilista ou determinista, trincheiras daquele tempo, assim como muitos anos depois recusei aceitar os rótulos de teorético, quantitativo, estruturalista ou qualquer outro. Enfim, os caminhos sáo muitos e creio que cada um deva tomar o caminho que considerar o mais correto, aquele no qual acredita. Apenas creio que isso deva ser feito sem fanatismo, sem julgar que a verdade foi finalmente encontrada, e não haveria mais o que procurar, sempre com muito espírito crítico, aceitando o pressuposto de que aquilo no que acredita pode não ser a verdade absoluta, portanto, suscetível de correção. Esse foi sempre o modo de ver pelo qual conduzo minhas atividades, quer de docente, quer de pesquisador. Nunca aceitei qualquer coisa como dogmática. Portanto, e coerentemente, diria: nunca aceitar nada como dogma, aceitar as idéias desde que existam argumentos que convençam, e enquanto tais argumentos se sustentarem, e não existirem outros que modifiquem o entendimento anterior, o modo de ver, de concluir. $E$ isto que considero importante, e não só em Geografia.

\section{O meio ambiente}

$E A$ - Nesses riltimos anos, mundialmente tem-se dado ênfase à questão da preserpafá̃o da natureza, naturalmente lidando com material que é estudado pelos geografos. Como o senhor pe a questão da defesa do meio ambiente?

$P P$ - Vamos considerar, antes de tudo, a questão geral da defesa do meio ambiente. Pessoalmente vejo o crescimento do interesse pela defesa do meio ambiente como alguma coisa extremamente positiva. A aquisição de uma consciência sempre mais viva, mais nítida, mais rica, da necessidade de preservar, conservar, proteger o meio ambiente, parece-me da mais alta importância. Repito que em princípio trata-se de algo muito positivo. Entretanto, cabe náo esquecer, em momento algum, o próprio homem. Preservar significa alguma coisa de que se fala há muitas décadas, $\mathbf{e}$ muito pelos próprios geógrafos, ou seja, equilíbrio ecológico, implicando presença do homem. Em outras palavras, defender o equilíbrio ecológico náo significa excluir o homem. Enfim, vejo os movimentos pela preservação como altamente positivos quando voltados para a conservação, proteçáo de alguma coisa que é extremamente dinâmica, que é viva, e que portanto sofre constantes, contínuas mudanças, e não quando voltados para alguma coisa que deva ser transformada em museu natural. É evidente que a natureza não deve ser transformada em museu pelo homem, porque dessa forma, o que se estaria propug- 
nando seria a própria expulsão do homem. No caso particular da Geografia, é um paradoxo que uma ciência que se tem dedicado muito ao estudo das relaçóes entre sociedade e ambiente geográfico, o qual, durante muitos anos, justificou na Universidade a presença de disciplina rotulada $O$ Homem e o Meio, não tenha merecido, no caso dos estudos relativos ao meio ambiente, a expressão a que na verdade faz jus. Há certo modismo nas atenções que se tem dado às questóes de meio ambiente. Ressalvado esse fato, entretanto, na realidade, essas questóes têm interessado cientistas de campos os mais diversificados. Hoje, verifica-se significativa presença de biólogos, na verdade, maior que a de geógrafos, embora esta última também se faça sentir. Talvez esse fato seja conseqüência de algumas correntes mais recentes no campo da ciência geográfica e tenham privilegiado direçóes que implicam marginalização desse problema. Convém ter em mente que sempre que o geógrafo trata de ecossistemas, estará tratando de alguma coisa que interessa os problemas ecológicos, naturalmente também de interesse do fitoecólogo, do zooecólogo e de outros cientistas. De qualquer forma, entretanto, o geógrafo não pode ficar alheio a esse tipo de preocupação.

\section{Importância da reforma universitária}

$E A$ - Foi de muita importancia a reforma universitária do ponto de vista da criafão dos cursos de pós-graduacão. Como o senbor pé a experiéncia da pós-graduafão? Marcou uma etapa nova no ensino da Geografia e na pesquisa?

$$
P P \text { - Creio que marcou. }
$$

\section{$E A-O$ senbor continua dando aulas?}

$P P$ - Não, e nem oriento alunos de pós-graduaçáo. Quando julguei que não deveria tardar o momento de aposentar-me, organizei minhas atividades para um período de aproximadamente cinco anos, de modo tal que durante esse período pudesse ver formados todos os meus alunos de pós-graduação. Todos se formaram. Mas voltando à questão da reforma, referida na pergunta anterior, creio ter sido muito importante. Cabe lembrar, todavia, que a própria Faculdade de Filosofia já de há muito havia inovado, dado que desde seus primeiros anos de existência mantinha o doutorado. Na verdade, foi a Faculdade de Filosofia que deu um sentido novo ao título de doutor que, até então, atribuía-se ao bacharel em Direito - todo bacharel era considerado doutor - e também ao formado em Medicina - o médico era necessariamente doutor. Continuou inovando, antecipando-se em relação ao conjunto da Universidade, criando seus cursos de pós-graduaçáo já na década de 1960. A partir dos primeiros anos dessa, não apenas manteve os cursos 
de doutorado, que vinham desde a década de 1930, mas criou os de mestrado, talvez como frutos do crescimento das experiências dos chamados cursos de Especialização, que funcionaram nos lustros anteriores. Os novos cursos de pós-graduação - doutorado e mestrado - foram criados nos anos de 1962-63. Dessa época datam também os novos cursos de pós-graduação em Geografia. Tenho ainda cópias dos regulamentos desses cursos. Mais tarde foram inseridos no quadro geral dos cursos de pós-graduação da Universidade de Sáo Paulo - início da década de 1970 - e logo no quadro desses cursos em âmbito nacional. Naturalmente, esse fato deu nova conotação ao conjunto. Creio que com a pós-graduaçáo houve um enriquecimento indiscutível do processo de formaçáo do estudante universitário e do professorado, à medida em que esses cursos constituíram uma sementeira para a formação e aprimoramento de docentes para a Universidade. Com a pós-graduação houve crescimento da pesquisa, sem dúvida; na pior das hipóteses, cada aluno de pós-graduação significa um pesquisador voltado para uma atividade específica e, portanto, uma significativa abertura em leque dos campos objetos de pesquisa. Por outro lado, e sem intenção de generalizar, em certos casos pode ter havido relativo empobrecimento das atividades didáticas. À medida em que a pós-graduação tornou-se um curso, passando a exigir a ministração de disciplinas teóricas, em determinados casos pode ter permitido que algumas atividades - tipos de disciplinas - que no passado foram ou teriam sido próprias da graduação, passassem para a pós-graduação, quem sabe mais ou menos enriquecidas quanto ao significado de seu conteúdo. Como seria de se esperar, disciplinas de pós-graduaçáo nem sempre significam alguma coisa necessariamente bastante elevada, assim como disciplinas de graduação podem revelar conteúdos de altíssimo padráo. De qualquer forma, cabe insistir, o enriquecimento foi indiscutível. É o que posso afirmar segundo meu conhecimento, naturalmente limitado, dados os parcos informes que tenho quanto aos outros cursos da Universidade. 